\title{
Farklı Çamur Yaşlarında Anaerobik/Aerobik/Anoksik Ardışık Kesikli Reaktörde Nutrient Giderimi
}

\author{
Nutrient Removal in Anaerobic/Aerobic/Anoxic Sequencing Batch Reactor at Different \\ Sludge Ages
}

\author{
Müslün Sara TUNÇ*a , Ayhan ÜNLÜ ${ }^{\mathrm{b}}$ \\ Fırat Üniversitesi, Mühendislik Fakültesi, Çevre Mühendisliği Bölümü, 23119, Elazığ
}

• Geliş tarihi / Received: 18.09.2019 • Düzeltilerek geliş tarihi / Received in revised form: $17.05 .2020 \quad$ • Kabul tarihi / Accepted: 23.05 .2020

\begin{abstract}
Öz
$\mathrm{Bu}$ çalışmada, ardışık kesikli bir reaktör ile sentetik atıksudan nutrient giderimi farklı çamur yaşlarında çalışılmıştır. Ardışı kesikli reaktör anaerobik (130 dakika), aerobik (330 dakika) ve anoksik (210 dakika) fazlar şeklinde işletilmiştir. Anoksik fazdan sonra 45 dakika çökelme ve 5 dakika boşaltma fazı uygulanmıştır. Reaktör 6 gün çamur yaşında işletildiğinde, ortalama olarak \%92 KOİ, \%81 NH4-N ve \%26 $\mathrm{PO}_{4}-\mathrm{P}$ giderimi gözlenmiştir. Çamur yaşı 10 günde sabit tutulduğunda ortalama olarak \%93 KOİ, \%90 NH4 $-\mathrm{N}$ ve $\% 13 \mathrm{PO}_{4}-\mathrm{P}$ giderimi sağlanmıştır. 15 günlük çamur yaşında ise ortalama olarak \%92 KOİ, \%79 NH4 $-\mathrm{N}$ ve $\% 17 \mathrm{PO}_{4}-\mathrm{P}$ giderimi elde edilmiștir. En yüksek KOİ (\%93) ve $\mathrm{NH}_{4}-\mathrm{N}(\% 90)$ giderimi 10 günlük çamur yaşında belirlenirken en iyi $\mathrm{PO}_{4}-\mathrm{P}$ giderimi 6 günlük çamur yaşında sağlanmıştır. KOİ ve $\mathrm{NH}_{4}-\mathrm{N}$ giderim verimi ile karşılaştırıldığında $\mathrm{PO}_{4}-\mathrm{P}$ için oldukça düşük giderim verimi gözlenmiştir.
\end{abstract}

Anahtar kelimeler: Ardışık Kesikli Reaktör, Çamur Yaşı, Nutrient Giderimi

\begin{abstract}
In this study, nutrient removal from synthetic wastewater by a sequencing batch reactor was studied at different sludge ages. The sequencing batch reactor was operated in anaerobic (130 minutes), aerobic (330 minutes) and anoxic (210 minutes) phases. After the anoxic phase, settling phase of 45 minutes and discharge phase of 5 minutes were applied. When the reactor was operated at sludge age of 6 days, average $92 \% \mathrm{COD}, 81 \% \mathrm{NH}_{4}-\mathrm{N}$ and $26 \% \mathrm{PO}_{4}-\mathrm{P}$ removal were observed. When the sludge age was kept constant at 10 days, $\mathrm{COD}, \mathrm{NH}_{4}-\mathrm{N}$ and $\mathrm{PO}_{4}-\mathrm{P}$ removal were achieved to be average 93\%, 90\% and 13\%, respectively. At sludge age of 15 days, average $92 \% \mathrm{COD}, 79 \% \mathrm{NH}_{4}-\mathrm{N}$ and $17 \% \mathrm{PO}-\mathrm{P}$ removal were obtained. The highest $\mathrm{COD}(93 \%)$ and $\mathrm{NH}_{4}-\mathrm{N}(90 \%)$ removal was determined at the sludge age of 10 days, while the best $\mathrm{PO}_{4}-\mathrm{P}$ removal was achieved at the sludge age of 6 days. Compared with $\mathrm{COD}$ and $\mathrm{NH}_{4}-\mathrm{N}$ removal efficiency, $\mathrm{PO}_{4}-\mathrm{P}$ removal efficiency was appeared very low.
\end{abstract}

Keywords: Sequencing Batch Reactor, Sludge Age, Nutrient Removal

\footnotetext{
*a M. Sara TUNÇ; saratunc@firat.edu.tr, Tel: (0424) 23700 00/8417, orcid.org/0000-0001-9907-0428

${ }^{\mathrm{b}}$ orcid.org/0000-0001-9577-6389
} 


\section{Giriş}

Azot ve fosfor, evsel ve endüstriyel atıksularda yaygın kirleticilerdir. İnsanoğlunu etkileyen çeşitli hastalıklar ve ötrofikasyon gibi bazı sorunlara neden olmalarından dolayı çevreye salınımları çok dikkat çekmektedir (Jiang vd., 2016). Bu nedenle hem azotun hem de fosforun giderilmesi su kirliliği kontrolü için hayati öneme sahiptir (Xu vd., 2013). Atıksulardan biyolojik nutrient gideriminin ötrofikasyon problemini önlemede etkili bir teknik olduğu kanıtlanmıştır (Chen vd., 2019). Biyolojik nutrient giderimi, sık1 deşarj gereksinimlerini karşılamak için en ekonomik ve sürdürülebilir teknik olarak kabul edilmektedir (Xu vd., 2013; Marin vd., 2016). Biyolojik nutrient giderimi, fosforun anaerobik salınımı ve aerobik alımı, nitrifikasyon ve denitrifikasyon gibi birçok biyokimyasal süreci kapsamaktadır. Biyolojik fosfor giderimi, fosfor biriktiren organizmaların hücrelerinde fosforun aerobik ortamda polifosfat olarak depolanması yoluyla sağlanmaktadır (Chen vd., 2019). Azotun biyolojik olarak giderimi nitrifikasyon ve denitrifikasyon olmak üzere iki ana prosesten oluşmaktadır. Nitrifikasyon, amonyum oksitleyen bakteriler tarafindan amonyumun nitrite oksitlendiği, sonra nitrit oksitleyen bakteriler tarafindan nitritin nitrata oksitlendiği ototrofik bakteriler tarafindan gerçekleştirilen aerobik bir prosestir. Denitrifikasyon, elektron alıcısı olarak nitrit ve/veya nitrat kullanılarak heterotrofik bakteriler tarafından gerçekleştirilen bir anoksik prosestir. Bu proseste, nitrat nitrite ve daha sonra nitrik oksit, azot oksit ve son olarak azot gazına indirgenmektedir (Marin vd., 2016).

Ardışık kesikli reaktör (AKR) sistemleri biyolojik nutrient gideriminde iyi bir potansiyel göstermiş̧tir. AKR kullanıldığında, tek bir reaktörde nitrifikasyon, denitrifikasyon ve fosfor gideriminin elde edilmesi mümkündür (Akin ve Ugurlu, 2004). AKR, doldur-boşalt tarzında işletilen bir çeşit aktif çamur arıtma sistemidir. AKR işletiminde, prosesler aynı tankta ardışı olarak gerçekleştirilmektedir (Sirianuntapiboon ve Yommee, 2006). Tüm AKR sistemlerde her bir arıtma döngüsü aşağıdaki kademeleri içermektedir: Doldurma, reaksiyon periyodu, çökelme, boşaltma ve dinlendirme (GarzonZúñiga ve González-Martínez, 1996). Biyolojik nutrient giderimi istendiğinde, reaksiyon periyodundaki basamaklar, belli sayı ve sırada anaerobik, anoksik ve aerobik işlemleri sağlamak için ayarlanmaktadır (Uygur vd., 2004). AKR'de, çökeltme havuzları ve debi dengeleme tankları gerekli değildir ve bu nedenle tesislerin ve işletme yönetiminin maliyetleri sürekli akışla çalışan çamur sistemlerinden çok daha düşüktür. Ayrıca, AKR'nin çevrim süreleri ve akış hızları gibi çalışma koşullarını değiştirmenin kolay olmasından dolayı faydaları vardır. Bu nedenle, AKR, özellikle küçük atık su arıtma tesisleri için etkili olarak kabul edilmektedir (Tsuneda vd., 2006). Bu çalışmada, anaerobik/aerobik/anoksik olarak işletilen ardışık kesikli reaktörün sentetik atıksudan nutrient giderim performans1 farkl1 çamur yaşı şartları altında araştırılmıştır.

\section{Materyal ve Metot}

Çalışma 1.2 L işletme hacimli ardışık kesikli bir reaktör (AKR)'de yürütülmüştür. AKR, $24 \pm 1^{\circ} \mathrm{C}$ 'de günde 2 döngü olarak işletilmiştir. Her bir döngü 130 dakika anaerobik, 330 dakika aerobik, 210 dakika anoksik, 45 dakika çökelme ve 5 dakika boşaltma fazı olmak üzere 12 saatten ibaret olmuştur. Her döngüde, anaerobik fazın ilk 1-2 dakikasında reaktöre $0.6 \mathrm{~L}$ sentetik atıksu beslenmiş ve her bir döngüde çökelme işlemi tamamlandiktan sonra boşaltma fazında reaktördeki üst sıvı karışımdan $0.6 \quad \mathrm{~L}$ boşaltılmıştır. Çökelme ve boşaltma fazları hariç, biyokütlenin askıda olmasını ve atıksu ile temasını sağlamak için manyetik karıştırıcı kullanılmıştır. Aerobik fazda havalandirma, hava pompas1 kullanılarak reaktöre yerleştirilen hava taşı ile sağlanmıştır. Reaktör, Malatya İleri Biyolojik Atıksu Arıtma Tesisi'nden alınan aktif çamur ile aşılanmıştır. Deneysel çalışmada sentetik atıksu kullanılmıştır. Sentetik atıksu $\mathrm{CH}_{3} \mathrm{COONa}_{3} 3 \mathrm{H}_{2} \mathrm{O}$ $(2260 \mathrm{mg} / \mathrm{L}),\left(\mathrm{NH}_{4}\right)_{2} \mathrm{SO}_{4}(236 \mathrm{mg} / \mathrm{L}), \mathrm{KH}_{2} \mathrm{PO}_{4}(66$ $\mathrm{mg} / \mathrm{L}), \mathrm{NaHCO}_{3}(590 \mathrm{mg} / \mathrm{L}), \mathrm{MgSO}_{4} .7 \mathrm{H}_{2} \mathrm{O}(50$ $\mathrm{mg} / \mathrm{L}$ ) ve $1 \mathrm{~mL}$ eser mineral çözeltisi içermiştir. Eser mineral çözeltisi litrede $100 \mathrm{mg}$ $\mathrm{ZnSO}_{4} .7 \mathrm{H}_{2} \mathrm{O}, 30 \mathrm{mg} \mathrm{MnCl}_{2} .4 \mathrm{H}_{2} \mathrm{O}, 300 \mathrm{mg}$ $\mathrm{H}_{3} \mathrm{BO}_{3}, 200 \mathrm{mg} \mathrm{CoCl} 2.6 \mathrm{H}_{2} \mathrm{O}, 10 \mathrm{mg} \mathrm{CuCl} 2.2 \mathrm{H}_{2} \mathrm{O}$, $10 \mathrm{mg} \mathrm{NiCl} 2.6 \mathrm{H}_{2} \mathrm{O}$ ve $30 \mathrm{mg} \mathrm{Na} 2 \mathrm{SeO}_{3}$ içermiştir. Sentetik atıksu içerisinde KOİ, azot ve fosfor sirasiyla $1000 \mathrm{mg} / \mathrm{L}, 50 \mathrm{mg} \mathrm{NH}_{4}-\mathrm{N} / \mathrm{L}$ ve $15 \mathrm{mg}$ $\mathrm{PO}_{4}-\mathrm{P} / \mathrm{L}$ 'dir. Sentetik atıksuyun başlangıç $\mathrm{pH}$ '1 7.2'e ayarlanmıştır. Reaktörde $\mathrm{pH}$ değeri kontrolü yapılmamıştır. AKR 6, 10 ve 15 gün olmak üzere üç farklı çamur yaşında işletilmiştir.

Her döngünün başında ve sonunda reaktörden numune alınıp filtreden geçirilmiş ve kimyasal oksijen ihtiyac1 (KOI), amonyum azotu $\left(\mathrm{NH}_{4}-\mathrm{N}\right)$, nitrit azotu $\left(\mathrm{NO}_{2}-\mathrm{N}\right)$, nitrat azotu $\left(\mathrm{NO}_{3}-\mathrm{N}\right)$ ve fosfat fosforu $\left(\mathrm{PO}_{4}-\mathrm{P}\right)$ analizleri yapılmıştır. $\mathrm{NH}_{4}-$ $\mathrm{N}, \quad \mathrm{NO}_{2}-\mathrm{N}, \quad \mathrm{NO}_{3}-\mathrm{N}$ ve $\mathrm{PO}_{4}-\mathrm{P}$ analizleri için standart test kitleri (Merck-Spectroquant) kullanılarak Merck Nova 60 Spectroquant cihazında gerçekleştirilmiştir. KOİ Standart 
Metotlar'a göre belirlenmiştir (APHA, 1989). Çözünmüş oksijen (ÇO) ve $\mathrm{pH}$ değeri multi-meter cihaz (Hach HQ40D) ile ölçülmüştür.

\section{Bulgular ve Tartışma}

\subsection{KOİ Giderim Verimi}

KOİ giderim veriminin çamur yaşı ile değişimi Şekil 1'de verilmiştir. 6, 10 ve 15 günlük çamur yaşında ortalama KOİ giderim verimi sırasıyla $\% 92, \% 93$ ve $\% 92$ olarak elde edilmiştir. Çalışılan tüm çamur yaşlarında KOİ giderim verimi yüksek olup hemen hemen aynı olarak gözlenmiştir.

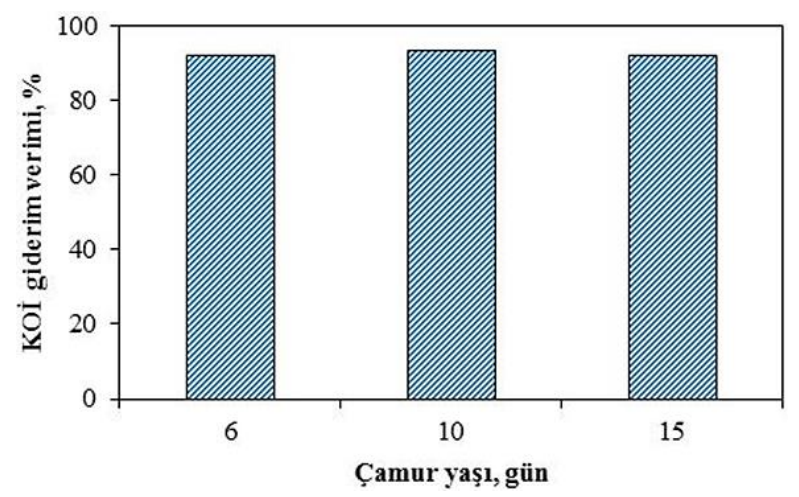

Şekil 1. KOİ giderim veriminin çamur yaşı ile değişimi

\section{2. $\mathrm{NH}_{4}-\mathrm{N}$ Giderim Verimi}

$\mathrm{NH}_{4}-\mathrm{N}$ giderim veriminin çamur yaşı ile değişimi Şekil 2'de verilmiştir. 6, 10 ve 15 günlük çamur yaşında elde edilen ortalama $\mathrm{NH}_{4}-\mathrm{N}$ giderim verimi sirasiyla $\% 81, \% 90$ ve $\% 79$ olarak belirlenmiştir. Şekilde görüldügü üzere, en yüksek giderim verimi 10 günlük çamur yaşında sağlanmıştır. Kargi ve Uygur (2002) tarafından yürütülen çalışmada da en yüksek $\mathrm{NH}_{4}-\mathrm{N}$ giderim verimi 10 günlük çamur yaşında sağlanmıştır. Yüksek çamur yaşı değerinde nitrifikasyon organizmalarının yaşlı popülasyonu düşük $\mathrm{NH}_{4}-\mathrm{N}$ giderim performansindan sorumlu olabilir (Kargi ve Uygur, 2002).

\section{3. $\mathrm{PO}_{4}-\mathrm{P}$ Giderim Verimi}

$\mathrm{PO}_{4}-\mathrm{P}$ giderim veriminin çamur yaşı ile değişimi Şekil 3'te verilmiştir. 6, 10 ve 15 günlük çamur yaşında elde edilen ortalama $\mathrm{PO}_{4}-\mathrm{P}$ giderim verimi sirasiyla $\% 26, \% 13$ ve $\% 17$ olarak gözlenmiştir. 6 günlük çamur yaşında giderim verimi, 10 ve 15 günlük çamur yaşındaki giderim veriminden daha yüksek bulunmuştur. Ancak, fosfor giderim verimleri oldukça düşüktür, dolayısıyla çıkış suyunda oldukça yüksek miktarda $\mathrm{PO}_{4}-\mathrm{P}$ belirlenmiştir. $\mathrm{Bu}$ sonuçlara göre, sistemde fosfat biriktiren organizmaların inhibe olduğu ve giderilen fosforun da hücre sentezinde kullanıldığı ifade edilebilir.

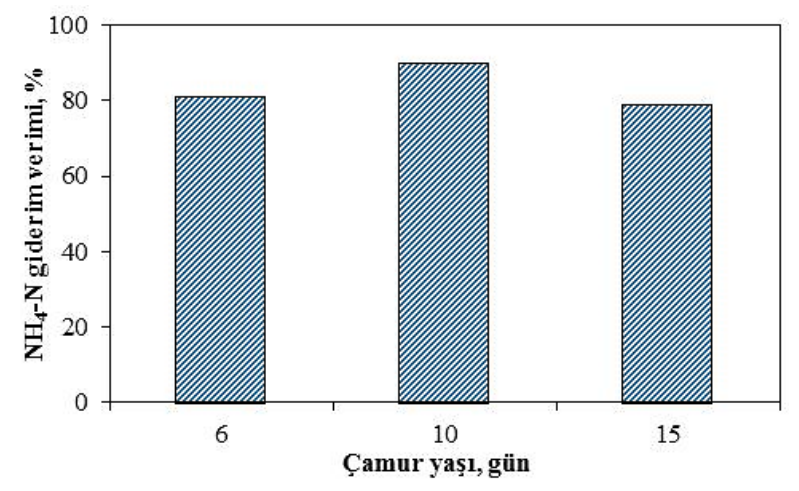

Şekil 2. $\mathrm{NH}_{4}-\mathrm{N}$ giderim veriminin çamur yaşı ile değişimi

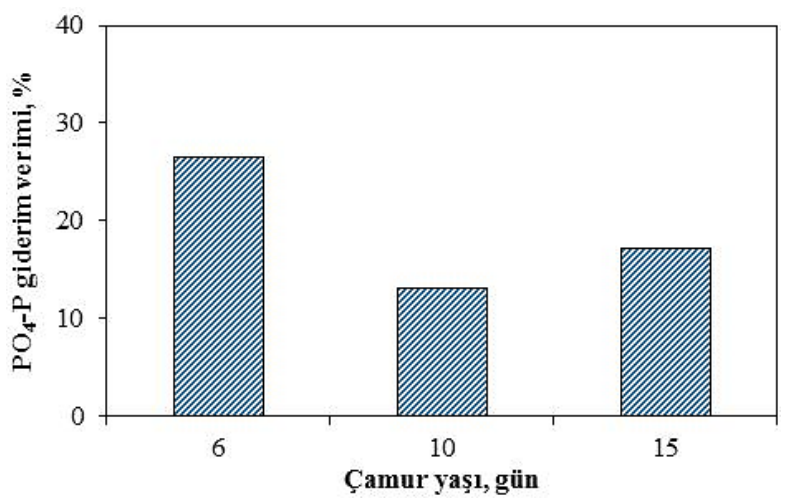

Şekil 3. $\mathrm{PO}_{4}-\mathrm{P}$ giderim veriminin çamur yaşı ile değişimi

\subsection{Döngü Süresince Nutrient Değişimi}

AKR, 10 günlük çamur yaşında işletildiğinde anaerobik, aerobik ve anoksik fazlarda $\mathrm{KOI}, \mathrm{NH}_{4-}$ $\mathrm{N}, \mathrm{NO}_{2}-\mathrm{N}, \mathrm{NO}_{3}-\mathrm{N}$ ve $\mathrm{PO}_{4}-\mathrm{P}$ konsantrasyonunun değişimi Şekil 4'te verilmiştir. Döngünün başında $455 \mathrm{mg} / \mathrm{L}$ olan KOİ konsantrasyonu anaerobik fazın sonunda $430 \mathrm{mg} / \mathrm{L}$ 'e düşmüş ve KOİ'nin sadece $\% 5$ 'i giderilmiştir. Anaerobik faz süresince $\mathrm{NH}_{4}-\mathrm{N}$ konsantrasyonunda önemli düzeyde değişim gözlenmemiştir. $\mathrm{PO}_{4}-\mathrm{P}$ konsantrasyonu hemen hemen aynı kalmış ve fosfor salınımı belirlenmemiştir.

Aerobik fazın başlıca amacı KOİ giderimini, nitrifikasyonu ve fosfor alımını sağlamaktır. $\mathrm{Bu}$ adımda KOİ konsantrasyonu $430 \mathrm{mg} / \mathrm{L}$ 'den 20 $\mathrm{mg} / \mathrm{L}$ 'e düşmüş ve KOİ'nin büyük çoğunluğu aerobik oksidasyon ile giderilmiştir. $\mathrm{NH}_{4}-\mathrm{N}$ konsantrasyonu $21.3 \mathrm{mg} / \mathrm{L}$ 'den $2.1 \mathrm{mg} / \mathrm{L}$ 'e düşmüştür. $\mathrm{Bu}$ fazda $5.6 \mathrm{mg} / \mathrm{L} \quad \mathrm{NO}_{2}-\mathrm{N}$ ve 2.5 $\mathrm{mg} / \mathrm{L} \mathrm{NO} \mathrm{NO}_{3}-\mathrm{N}$ üretilmiştir. Sonuçlardan görüldüğg̈ 
üzere, aerobik fazda tam nitrifikasyon gerçekleşmemiştir. Aerobik fazda nitrata kadar tam nitrifikasyon gerçekleşmediği için sistemde nitrit birikimi gözlenmiştir. Aşağıdaki denklem kullanılarak reaktörde nitrit birikim oran1 belirlenebilmektedir (Guo vd., 2009).

Nitrit Birikim Oranı

$=\frac{\mathrm{NO}_{2}-\mathrm{N}}{\mathrm{NO}_{2}-\mathrm{N}+\mathrm{NO}_{3}-\mathrm{N}} \times \% 100$

Denklem (1) kullanılarak reaktördeki nitrit birikimi oranı $\% 69$ olarak belirlenmiştir. Reaktörde nitritin birikmesi, nitrit oksitleyen bakterilerin inhibe olduğunu göstermektedir. Nitrit birikiminde ÇO konsantrasyonu, sicaklık, $\mathrm{pH}$ ve serbest amonyak konsantrasyonu etkili faktörlerdir. Ciudad vd. (2005) $1.4 \mathrm{mg} / \mathrm{L}$ ÇO konsantrasyonunda \%75 ve Ruiz vd. (2003) 0.7 $\mathrm{mg} / \mathrm{L} \quad$ ÇO konsantrasyonunda \%65 nitrit birikimini gözlemlemişlerdir. $\mathrm{Bu}$ çalışmada, aerobik fazda reaktördeki ÇO konsantrasyonu düşük olmadığından dolayı, ÇO konsantrasyonunun nitrit birikiminden sorumlu faktör olmadığı düşünülmektedir. Serbest amonyak konsantrasyonu; amonyum konsantrasyonu, $\mathrm{pH}$ ve sicaklığa bağlı olmaktadır. $\mathrm{pH}$ ve sicaklığın artmasiyla serbest amonyak konsantrasyonu artmaktadır. Reaktörde sicaklık $24 \pm 1{ }^{\circ} \mathrm{C}$ olup sicaklık değerinde artı̧̧ söz konusu olmamıştır. Ancak, aerobik fazda $\mathrm{pH}$ değeri yükselmiş ve dolayısıyla serbest amonyak konsantrasyonu da artmıştır. Bu durumda, serbest amonyak nitrit oksitleyen bakterileri inhibe ederek nitrit birikimine neden olmuştur. Anthonisen vd.'e (1976) göre amonyum oksitleyen bakteriler 10$150 \mathrm{mg} / \mathrm{L}$ ve nitrit oksitleyen bakteriler 0.1-1.0 $\mathrm{mg} / \mathrm{L}$ serbest amonyak konsantrasyonu ile inhibe olmaktadır (Aslan vd., 2009). Benzer şekilde, Park ve Bae (2009) nitrit oksitleyen bakterilerin $0.7 \mathrm{mg} / \mathrm{L}$ serbest amonyak konsantrasyonunda inhibe olduğunu rapor etmiştir.

Sistemde gözlenen $\mathrm{pH}$ yükselmesi $\mathrm{CO}_{2}$ sıyırması ve KOİ'nin hızlı tüketimi ile meydana gelmiştir (Kumar ve Chaudhari, 2003; Guo vd., 2009). Çalışmalarda, asetat yaygın şekilde kullanılan bir karbon kaynağıdır. Bu çalışmada da asetat karbon kaynağ 1 olarak kullanılmıştır. Aerobik şartlar altında asetatın teorik oksidasyonu aşağıdaki gibi olmaktadır:

$$
\mathrm{CH}_{3} \mathrm{COO}^{-}+\mathrm{H}^{+}+2 \mathrm{O}_{2} \rightarrow 2 \mathrm{CO}_{2}+2 \mathrm{H}_{2} \mathrm{O}
$$

Denklem (2) asetat oksidasyonunun $1 \mathrm{~mol} / 1 \mathrm{~mol}$ oranında hidrojen iyonlarını tükettiğini, yani asetat oksitlendiğinde çözelti $\mathrm{pH}$ 'sında bir artışın kaçınılmaz olduğunu göstermektedir. Havalandırmanın yaklaşık ilk 1 saati içinde KOİ tüketilmiştir. $\mathrm{Bu}$ durum, reaktörde 9 değerine kadar pH artışına yol açmıştır. Literatürde, nitrifikasyon için optimum pH'nın 7.8-8.0 aralığına düştüğü ve $\mathrm{pH}$ artışından dolayı serbest amonyağın nitrifikasyon gerçekleştiren bakterilerin aktivitesini inhibe ettiği rapor edilmiştir (Yang vd., 2004).

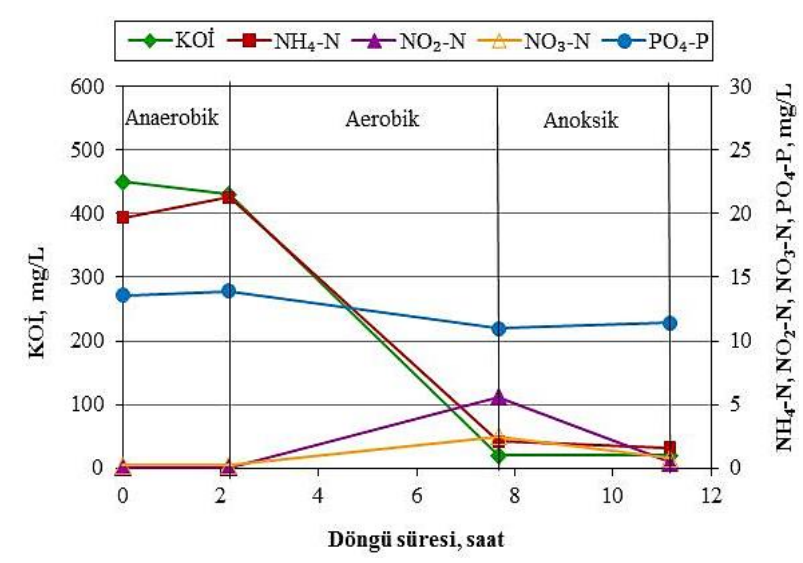

Şekil 4. Döngü süresince KOİ, azot ve fosfor konsantrasyonunun değişimi

Aerobik fazda, $\mathrm{PO}_{4}-\mathrm{P}$ konsantrasyonu ise 13.6 $\mathrm{mg} / \mathrm{L}$ 'den $11 \mathrm{mg} / \mathrm{L}$ 'e düşmüş ve çok düşük bir giderim verimi gözlenmiştir. Anaerobik fazda fosfor salınımı gerçekleşmediğinden dolayı, aerobik fazda da aşırı fosfor alımı sağlanmamıştır. Anaerobik fazda fosfor salınımının ve aerobik fazda aşı1 fosfor alımının gerçekleşmemesi sistemde fosfor biriktiren organizmaların inhibe olduğunu göstermektedir. Aerobik fazda giderilmiş olan fosfor hücre sentezinde kullanılmıştır. Çıkış suyunda yüksek konsantrasyonda fosfor gözlenmiştir. Nitrite kadar kısmi nitrifikasyon, havalandırma için daha az enerji gereksinimi ve takip eden denitrifikasyonda daha az karbon kaynağı gereksinimi gibi avantajlar sağlamaktadır (Guo vd., 2009). Ancak, nitrit birikiminin avantajları olduğu gibi biyolojik azot giderim prosesi ile biyolojik fosfor giderim prosesinin kombinasyon halinde uygulandiğ 1 prosesler için de dezavantajları söz konusudur. Fosfor alımı üzerinde olumsuz etkisi bulunmaktadır. Saito vd. (2004), bir çalışmalarında $2 \mathrm{mg} \mathrm{N} / \mathrm{L}$ nitritin aerobik fosfat alımında ciddi bir inhibisyona ve $6 \mathrm{mg} \mathrm{N} / \mathrm{L}$ 'den daha fazla nitritin hemen hemen tam inhibisyona neden olduğunu gözlemlemişlerdir. Bu çalışmada, nitrit birikimi biyolojik fosfor gideriminin gözlenmemesinde etkili bir husus olabilir. 
Peng vd. (2006) bir çalışmalarında sabit hava debisinde ilk 3 aerobik bölgede ÇO konsantrasyonu $2 \mathrm{mg} / \mathrm{L}$ 'de korunmuştur. 4. aerobik bölgede ÇO konsantrasyonu değişimi gözlenmiş ve aerobik bölgenin sonunda 2.3-5.28 mg/L'e kadar yükselmiştir. Bu periyot esnasında fosfor giderim veriminin dramatik olarak bozulduğunu gözlemlemişlerdir. Çalışmamızda 5.5 saat olan aerobik fazda reaktördeki ÇO konsantrasyonu $0 \mathrm{mg} / \mathrm{L}$ 'den başlayıp KOİ'nin tükendiği ilk 1 saate kadar 2-3 mg/L olmuştur. Organik madde tükendikten sonra ÇO konsantrasyonu 5.0-6.5 $\mathrm{mg} / \mathrm{L}$ 'e kadar yükselmiştir. Sistem yaklaşık 4.5 saat bu yüksek oksijen konsantrasyonunda havalandırılmış olmaktadır. $\mathrm{Bu}$ durum da, sistemde fosfor salınımının ve alımının engellenmesinde etkili bir husus olabilir.

AKR'de anoksik fazın temel amac1 denitrifikasyonu sağlamaktır. Anoksik fazda $\mathrm{NO}_{2}-$ $\mathrm{N} 0.43 \mathrm{mg} / \mathrm{L}$ ve $\mathrm{NO}_{3}-\mathrm{N} 0.8 \mathrm{mg} / \mathrm{L}$ değerine düşmüştür. Nitrit ve nitrat denitrifikasyon ile sistemden giderilmiştir. $\mathrm{Bu}$ fazda, reaktöre harici karbon kaynağı eklenmemiştir, dolayısıyla denitrifikasyonun içsel solunum yoluyla gerçekleştiği söylenebilir.

\section{Sonuçlar}

$\mathrm{Bu}$ çalışmada, anaerobik/aerobik/anoksik olarak işletilen AKR'de nutrient giderim performans1 üzerinde çamur yaşının $(6,10$ ve 15 gün) etkisi değerlendirilmiştir. Farklı çamur yaşından KOİ giderme verimi etkilenmezken, $\mathrm{NH}_{4}-\mathrm{N}$ ve $\mathrm{PO}_{4}-\mathrm{P}$ giderim verimi etkilenmiştir. AKR'de KOİ giderim verimi üzerinde çamur yaşının etkisinin benzer olduğu görülmüştür. $\mathrm{NH}_{4}-\mathrm{N}$ ve $\mathrm{PO}_{4}-\mathrm{P}$ için en iyi giderim verimi sırasiyla 10 ve 6 günlük çamur yaşında sağlanmıştır.

\section{Teşekkür}

$\mathrm{Bu}$ makale M. Sara Tunç'un doktora tezinden üretilmiştir. Çalışmamızı 1534 proje numarası ile destekleyen Fırat Üniversitesi Bilimsel Araştırma Projeleri Koordinasyon Birimi'ne teşekkürlerimizi sunarız. Makalenin inceleme ve değerlendirme aşamasında yapmış oldukları katkılardan dolayı editör ve hakem/hakemlere de teşekkür ederiz.

\section{Kaynaklar}

Akin, B.S. ve Ugurlu, A., 2004. The Effect of an Anoxic Zone on Biological Phosphorus Removal by a Sequential Batch Reactor. Bioresource Technology, 94, 1-7.
APHA, AWWA, WCPF, 1989. Standard Methods for the Examination of Water and Wastewater. $17^{\text {th }}$ Edition, American Public Health Association, Washington, D.C.

Aslan, Ş., Miller, L. ve Dahab, M., 2009. Ammonium Oxidation via Nitrite Accumulation Under Limited Oxygen Concentration in Sequencing Batch Reactors. Bioresource Technology, 100, 659-664.

Chen, H., Zhou, Y., Hu, X., Tian, K. ve Zhang, J., 2019. Effects of Chlortetracycline on Biological Nutrient Removal from Wastewater. Science of the Total Environment, 647, 268-274.

Ciudad, G., Rubilar, O., Muñoz, P., Ruiz, G., Chamy, R., Vergara, C. ve Jeison, D., 2005. Partial Nitrification of High Ammonia Concentration Wastewater as a Part of a Shortcut Biological Nitrogen Removal Process. Process Biochemistry, 40, 1715-1719.

Garzon-Zúñiga, M.A. ve González-Martínez, S., 1996. Biological Phosphate and Nitrogen Removal in a Biofilm Sequencing Batch Reactor. Water Science and Technology, 34(1-2), 293-301.

Guo, J., Peng, Y., Wang, S., Zhenge, Y., Huang, H. ve Wang, Z., 2009. Long-Term Effect of Dissolved Oxygen on Partial Nitrification Performance and Microbial Community Structure. Bioresource Technology, 100, 2796-2802.

Jiang, Y., Wang, H., Shang, Y. ve Yang, K., 2016. Simultaneous Removal of Aniline, Nitrogen and Phosphorus in Aniline-Containing Wastewater Treatment by Using Sequencing Batch Reactor. Bioresource Technology, 207, 422-429.

Kargi, F. ve Uygur, A., 2002. Nutrient Removal Performance of a Sequencing Batch Reactor as a Function of the Sludge Age. Enzyme and Microbial Technology, 31, 842-847.

Kumar, B.M. ve Chaudhari, S., 2003. Evaluation of Sequencing Batch Reactor (SBR) and Sequencing Batch Biofilm Reactor (SBBR) for Biological Nutrient Removal from Simulated Wastewater Containing Glucose as Carbon Source. Water Science and Technology, 48(3), 73-79.

Marin, J.C.A., Caravelli, A.H. ve Zaritzky, N.E., 2016. Nitrification and Aerobic Denitrification in Anoxic-Aerobic Sequencing Batch Reactor. Bioresource Technology, 200, 380-387.

Park, S. and Bae, W., 2009. Modeling Kinetics of Ammonium Oxidation and Nitrite Oxidation Under Simultaneous Inhibition by Free Ammonia and Free Nitrous Acid. Process Biochemistry, 44(6), 631-640. 
Peng, Y.Z., Wang, X.L. ve Li, B.K., 2006. Anoxic Biological Phosphorus Uptake and the Effect of Excessive Aeration on Biological Phosphorus Removal in the $\mathrm{A}^{2} \mathrm{O}$ Process. Desalination, 189, 155-164.

Ruiz, G., Jeison, D. ve Chamy, R., 2003. Nitrification with High Nitrite Accumulation for the Treatment of Wastewater with High Ammonia Concentration. Water Research, 37, 1371-1377.

Saito, T., Brdjanovic, D. ve van Loosdrecht, M.C.M., 2004. Effect of Nitrit on Phosphate Uptake by Phosphate Accumulating Organisms. Water Research, 38, 3760-3768.

Sirianuntapiboon, S. ve Yommee, S., 2006. Application of a New Type of Moving Bio-Film in Aerobic Sequencing Batch Reactor (AerobicSBR). Journal of Environmental Management, 78, 149-156.

Tsuneda, S., Ohno, T., Soejima, K. ve Hirata, A., 2006. Simultaneous Nitrogen and Phosphorus
Removal Using Denitrifying PhosphateAccumulating Organisms in a Sequencing Batch Reactor. Biochemical Engineering Journal, 27, 191-196.

Uygur, A., Kargı, F. ve Başkaya H.S., 2004. Ardışık Zamanlı Kesikli Biyo-Reaktörde Biyolojik Nutrient Gideriminde Hidrolik Bekleme Süresinin Optimizasyonu. Uludağ Üniversitesi Mühendislik-Mimarlık Fakültesi Dergisi, 9(1), 161-169.

Xu, D., Chen, H., Li, X., Yang, Q., Zeng, T., Luo, K. ve Zeng, G., 2013. Enhanced Biological Nutrient Removal in Sequencing Batch Reactors Operated as Static/Oxic/Anoxic (SOA) Process. Bioresource Technology, 143, 204-211.

Yang, S.F., Tay, J.H. ve Liu, Y., 2004. Inhibition of Free Ammonia to the Formation of Aerobic Granules. Biochemical Engineering Journal, 17, 41-48. 